\title{
Rapid Development of Intestinal Type Gastric Adenocarcinoma
}

\author{
Young S. Oh Benson T. Massey \\ Division of Gastroenterology and Hepatology, Medical College of Wisconsin, \\ Milwaukee, Wisc., USA
}

\section{Key Words}

Gastric cancer $\cdot$ Endoscopic ultrasonography $\cdot$ Metaplasia $\cdot$ Atrophic gastritis

\begin{abstract}
Intestinal type gastric adenocarcinoma is felt to develop over a protracted time period through a series of defined steps. Several potential risk factors for the development of gastric cancer have been identified, including a family history of gastric cancer and Helicobacter pylori infection. We present the case of a patient with neither risk factor who progressed in a 14 month time frame from histologically normal gastric mucosa to early stage intestinal type gastric adenocarcinoma in the setting of diffuse gastric intestinal metaplasia and atrophic gastritis. This patient's presentation conflicts with our current understanding of the development of intestinal type gastric adenocarcinoma.
\end{abstract}

\section{Introduction}

The most common histologic variant of gastric adenocarcinoma is the intestinal type. One model for the development of intestinal type gastric cancer is a prolonged progression from atrophic gastritis to intestinal metaplasia (IM) followed by dysplasia and ultimately cancer $[1]$.

Helicobacter pylori (H. pylori) infection has been shown to be an important risk factor for the development of gastric adenocarcinoma [2-4]. Other potential risk factors for the development of gastric cancer include cigarette smoking, high salt intake, family history of gastric cancer, and pernicious anemia [5-8].

We present a patient who progressed in 14 months from histologically documented normal gastric mucosa to moderately differentiated intestinal type adenocarcinoma in the background of atrophic gastritis and IM. 


\begin{tabular}{|c|c|c|c|}
\hline $\begin{array}{r}\text { Case Reports in } \\
\text { castroenterolowy }\end{array}$ & $\begin{array}{l}\text { Case Rep Gastroenterol 2011;5:192-195 } \\
\text { DOI: 10.1159/000326960 }\end{array}$ & $\begin{array}{l}\text { Published online: } \\
\text { April 13, } 2011\end{array}$ & \begin{tabular}{|l} 
@ 2011 S. Karger AG, Basel \\
ISSN $1662-0631$ \\
www.karger.com/crg
\end{tabular} \\
\hline
\end{tabular}

\section{Case Report}

The patient is a 74-year-old African-American female who initially presented in 2008 with odynophagia. Upper endoscopy performed at that time was unremarkable with the exception of a lipoma in the proximal stomach; mucosal biopsies from this area were unremarkable, including a Warthin-Starry stain for $H$. pylori. She then presented with oropharyngeal dysphagia approximately 7 months later. The evaluation was notable for a cervical esophageal web on esophagram, which was confirmed during repeat upper endoscopy in July 2009. Esophageal dilation was performed at that time and the patient's dysphagia initially improved; random biopsies obtained from the antrum of the stomach and esophagus were both normal.

The patient reported recurrent dysphagia in September 2010 without overt gastrointestinal bleeding, early satiety, nausea, vomiting, or unintentional weight loss. Repeat upper endoscopy demonstrated a presumptive recurrent proximal esophageal web that was successfully dilated as well as a $1 \mathrm{~cm}$ nodular area with overlying friability and depressed center in the body of the stomach that was not present on prior upper endoscopies (fig. 1). Biopsies from this area demonstrated intramucosal carcinoma and IM without evidence of $H$. pylori infection. Subsequent random gastric biopsies throughout the stomach demonstrated diffuse IM. Radial array endoscopic ultrasound (EUS) (GF-UE160, Olympus America Incorporated, Center Valley, Pa.) examination was performed to assess the feasibility of endoscopic mucosal resection of the nodular area in the stomach. EUS demonstrated no enlarged perigastric lymph nodes or abnormalities in the visualized left lobe of the liver but invasion of the nodular lesion into the

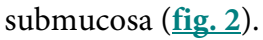

Given the depth of invasion of the lesion by EUS, endoscopic mucosal resection was not performed and the patient was referred for surgery. Preoperative CT chest, abdomen, and pelvis as well as PET-CT did not demonstrate evidence of locally advanced or metastatic disease. The patient underwent subtotal gastrectomy with Roux-en-Y reconstruction without complications. The final pathology demonstrated pT1b, pN0, pMX intestinal type moderately differentiated adenocarcinoma in the setting of atrophic gastritis and extensive IM with no malignancy at the resection margins.

The patient's past medical history is notable for early stage squamous cell carcinoma of the left vocal cord that had been definitively treated with external beam radiation in 2002 . She reported a 40 pack-year cigarette smoking history and had quit smoking in 2002. Her family history is negative for gastric cancer and the patient was born and raised in the United States.

\section{Discussion}

It is generally believed that the development of intestinal type gastric cancer is a prolonged process starting with the development of atrophic gastritis followed by IM. While this patient does have potential risk factors for the development of gastric cancer, namely a history of cigarette smoking and being of African-American descent, the rapid progression in 14 months from normal gastric mucosa to atrophic gastritis, IM, and cancer is unusual and contradicts the paradigm noted above. Other risk factors for the development of gastric cancer such as $H$. pylori infection, family history of gastric cancer, and pernicious anemia were not present and the patient was not from an area with a high prevalence of gastric cancer. Presumably, other unrecognized risk factors contributed to this patient's presentation.

Gastric IM is a common entity that has been estimated to occur in up to $50 \%$ of patients in Western countries [9]. Some investigators have suggested that endoscopic surveillance may be beneficial in patients with atrophic gastritis or gastric IM $[10,11]$. However, surveillance of all patients with gastric IM is controversial in Western countries given the low incidence of gastric cancer $[12,13]$. Irrespective of this issue, endoscopic screening was not an option in this patient since the diagnosis of gastric IM was made at the same time as the diagnosis of gastric cancer. 


\begin{tabular}{c|l|l|l}
$\begin{aligned} \text { Case Reports in } \\
\text { Gastroenterology }\end{aligned}$ & $\begin{array}{l}\text { Case Rep Gastroenterol 2011;5:192-195 } \\
\text { DOl: 10.1159/000326960 }\end{array}$ & $\begin{array}{l}\text { Published online: } \\
\text { April 13, 2011 }\end{array}$ & $\begin{array}{l}\text { O 2011 S. Karger AG, Basel } \\
\text { ISSN 1662-0631 } \\
\text { www.karger.com/crg }\end{array}$ \\
\hline
\end{tabular}

This case is the first to our knowledge that documents the rapid development of intestinal type gastric adenocarcinoma in a patient with previously normal gastric mucosa, specifically without a precancerous lesion such as IM. Further studies to identify previously unknown risk factors for gastric cancer as well as to better define which patients with atrophic gastritis or gastric IM are at higher risk for developing dysplasia and cancer are needed.

\section{Disclosure Statement}

The authors have no conflicts of interest to declare.

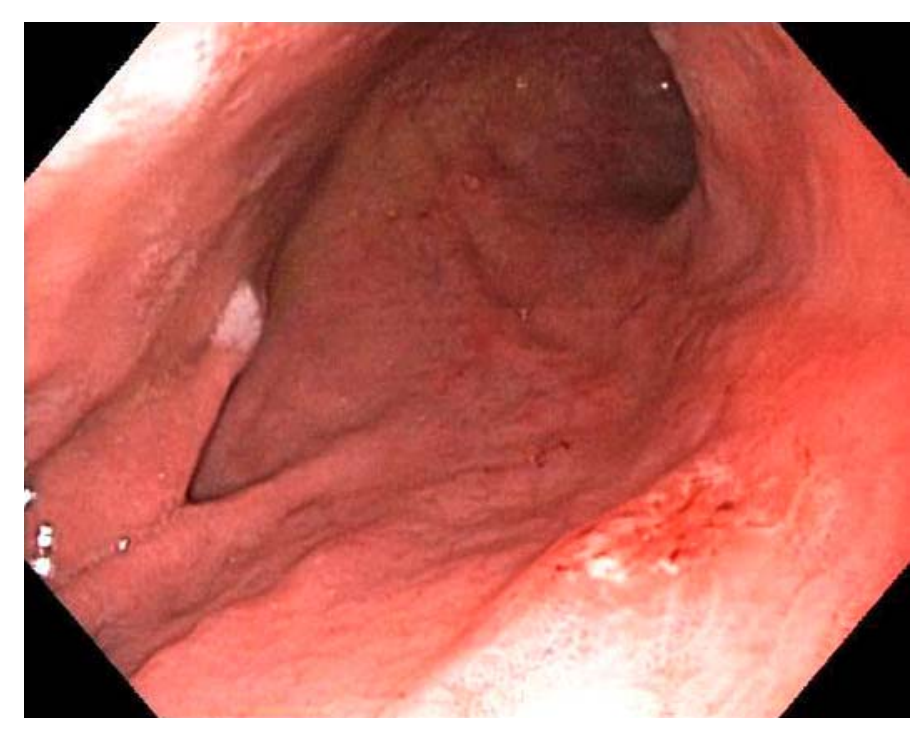

Fig. 1. Endoscopic appearance of the nodular malignant lesion in the stomach. 


\begin{tabular}{r|l|l|l}
$\begin{aligned} \text { Case Reports in } \\
\text { Gastroenterology }\end{aligned}$ & $\begin{array}{l}\text { Case Rep Gastroenterol 2011;5:192-195 } \\
\text { Dol: 10.1159/000326960 }\end{array}$ & $\begin{array}{l}\text { Published online: } \\
\text { April 13, 2011 }\end{array}$ & $\begin{array}{l}\text { O 2011 S. Karger AG, Basel } \\
\text { ISSN 1662-0631 } \\
\text { www.karger.com/crg }\end{array}$ \\
\hline
\end{tabular}

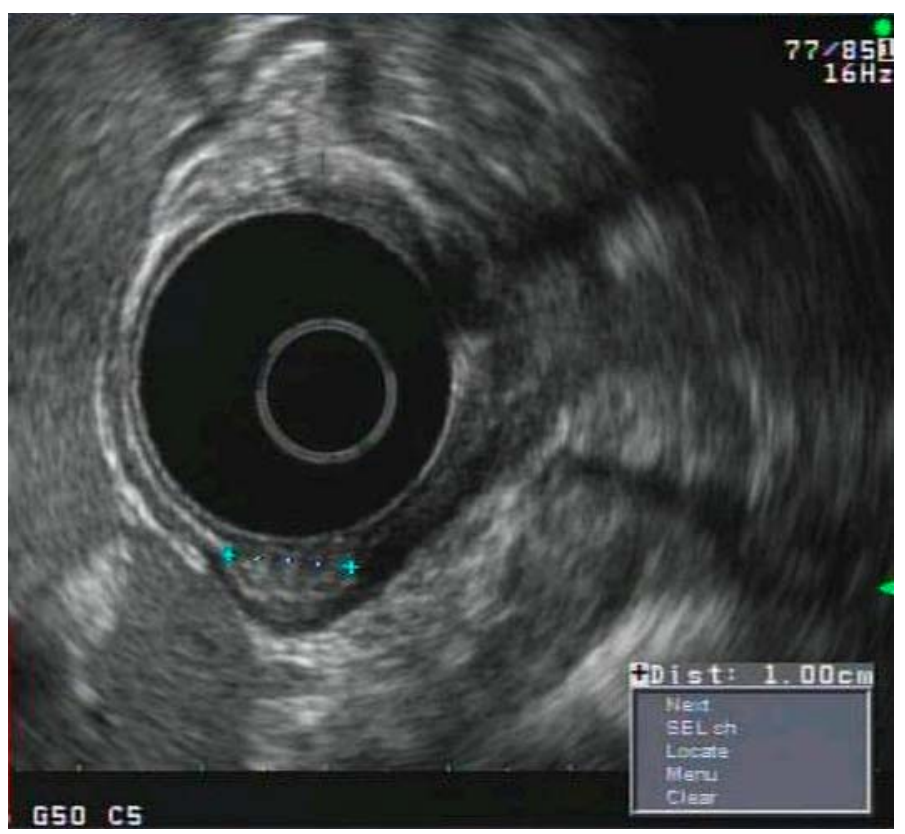

Fig. 2. EUS of the stomach showing invasion of the malignant lesion into the submucosal layer.

\section{References}

1 Correa P: A human model of gastric carcinogenesis. Cancer Res 1988;48:3554-3560.

$\checkmark 2$ Parsonnet J, Friedman GD, Vandersteen DP, et al: Helicobacter pylori infection and the risk of gastric carcinoma. N Engl J Med 1991;325:1127-1131.

$\checkmark 3$ Forman D, Newell DG, Fullerton F, et al: Association between infection with Helicobacter pylori and risk of gastric cancer: evidence from a prospective investigation. Br Med J 1991;302:1302-1305.

4 Nomura A, Stemmermann GN, Chyou PH, et al: Helicobacter pylori infection and gastric carcinoma among Japanese Americans in Hawaii. N Engl J Med 1991;325:1132-1136.

5 González CA, Pera G, Agudo A, et al: Smoking and the risk of gastric cancer in the European Prospective Investigation into Cancer and Nutrition (EPIC). Int J Cancer 2003;107:629-634.

6 Joossens JV, Hill MJ, Elliott P, et al: Dietary salt, nitrate and stomach cancer mortality in 24 countries. Int J Epidemiol 1996;25:494-504.

7 Palli D, Galli M, Caporaso NE, et al: Family history and risk of stomach cancer in Italy. Cancer Epidemiol Biomarkers Prev 1994;3:15-18.

8 Hsing AW, Hansson LE, McLaughlin JK, et al: Pernicious anemia and subsequent cancer. A population-based cohort study. Cancer 1993;71:745-750.

-9 Fennerty MB, Emerson JC, Sampliner RE, et al: Gastric intestinal metaplasia in ethnic groups in the southwestern United States. Cancer Epidemiol Biomarkers Prev 1992;1:293-296.

10 Whiting JL, Sigurdsson A, Rowlands DC, et al: The long term results of endoscopic surveillance of premalignant gastric lesions. Gut 2002;50:378-381.

11 Hassan C, Zullo A, Di Giulio E, et al: Cost-effectiveness of endoscopic surveillance for gastric intestinal metaplasia. Helicobacter 2010;15:221-226.

$\checkmark 12$ de Vries AC, van Grieken NCT, Looman CWN, et al: Gastric cancer risk in patients with premalignant gastric lesions: a nationwide cohort study in the Netherlands. Gastroenterology 2008;134:945-952.

-13 Fennerty MB: Gastric intestinal metaplasia on routine endoscopic biopsy. Gastroenterology 2003;125:586-590. 